\title{
Process for Producing Nano-Alpha-Alumina Powder
}

\author{
Fatemeh Mirjalili, ${ }^{1}$ Luqman Chuah Abdullah, ${ }^{2,3}$ Hasmaliza Mohamad, ${ }^{4}$ \\ A. Fakhru'l-Razi, ${ }^{2}$ A. B. Dayang Radiah, ${ }^{2}$ and R. Aghababazadeh ${ }^{5}$ \\ ${ }^{1}$ Maybod Branch, Islamic Azad University, Maybod, Iran \\ ${ }^{2}$ Department of Chemical \& Environmental Engineering, Faculty of Engineering, University Putra Malaysia, \\ 43400 Serdang, Selangor, Malaysia \\ ${ }^{3}$ Institute of Tropical Forestry and Forest Products (INTROP), University Putra Malaysia, 43400 Serdang, Selangor, Iran \\ ${ }^{4}$ School of Material \& Mineral Resources Engineering, University Sains Malaysia, Seri AMpangan 14300, Nibong Tebal, \\ Pulau Pinag, Malaysia \\ ${ }^{5}$ Institute for Colorants, Paint and Coatings, Tehran 16688-14811, Iran \\ Correspondence should be addressed to Fatemeh Mirjalili,fm.mirjalili@gmail.com
}

Received 21 March 2011; Accepted 18 April 2011

Academic Editor: C. Malagú

Copyright ( $\odot 2011$ Fatemeh Mirjalili et al. This is an open access article distributed under the Creative Commons Attribution License, which permits unrestricted use, distribution, and reproduction in any medium, provided the original work is properly cited.

\begin{abstract}
This paper is trying to explore the effect of stirring time on the synthesis of nano- $\alpha$-Alumina particles. In this study, alumina nanoparticles were synthesized through alkoxide route using sol-gel method, where aqueous solutions of aluminum isopropoxide and $0.5 \mathrm{M}$ aluminum nitrate nanohydrate were used for preparing alumina sol. Sodium dodecylbenzen sulfonate (SDBS) was used as the surfactant stabilizing agent. The prepared solution was stirred at different times $(24,36,48$, and 60 hours $)$ at $60^{\circ} \mathrm{C}$. The Samples were, then, characterized by X-ray diffraction, thermogravimetry analysis (TGA), differential scanning calorimetry (DSC), scanning electron microscopy (SEM) and Transmission Electron Microscopy(TEM). The introduction of different stirring times affected the particle size and shape and the degree of aggregation. By increasing the stirring time, (starting from 24 to 48 hours) the particle size decreased, but agglomeration became hard for 60 hours of stirring time. The finest particle size (20-30 nm) was obtained at 48 -hour stirring time.
\end{abstract}

\section{Introduction}

Alumina is one of the most widely used ceramic materials as catalysts, catalyst supports and absorbents, and also wear resistant coating [1]. It can be prepared through methods such as sol-gel [2,3], hydrothermal [4], coprecipitation, mechanical milling, vapor-phase reaction and combustion methods $[5,6]$. However, nanoscale alpha-alumina $(\alpha-$ $\mathrm{Al}_{2} \mathrm{O}_{3}$ ) powder is difficult to obtain. It is due to two reasons first, $\alpha-\mathrm{Al}_{2} \mathrm{O}_{3}$ is in a stable phase after calcining at high temperature, which easily prompts the grain growth of powder and makes it difficult to get nanoscale particles; secondly, $\alpha-\mathrm{Al}_{2} \mathrm{O}_{3}$ particles tend to aggregate during dehydration process in wet chemistry method. Therefore, it is necessary to develop a new method to overcome this problem $[7,8]$. Sol-gel synthesis offers relatively inexpensive scale processing of mixed oxide materials with a good control over the stoichiometry and morphology which helps to tailor the required materials on atomic scale to suit specific applications [5].

This study tends to synthesize nanosized $\alpha-\mathrm{Al}_{2} \mathrm{O}_{3}$ by controlling the particle size, distribution, and shape.

\section{Material and Method}

Aluminum isopropoxide $\mathrm{Al}\left(\mathrm{OC}_{3} \mathrm{H}_{7}\right)_{3}$ (Merck, German), aluminum nitrate nonahydrate $\mathrm{Al}\left(\mathrm{NO}_{3}\right)_{3} \cdot 9 \mathrm{H}_{2} \mathrm{O}$ (Merck, German), and Sodium dodecylbenzen sulfonate (SDBS) (Merck, German) were used as raw materials to prepare nano- $\alpha-\mathrm{Al}_{2} \mathrm{O}_{3}$. The starting solution was prepared through using aluminum isopropoxide and $0.5 \mathrm{M}$ aluminum nitrate aqueous solution as a solvent with the water purity of $99 \%$ and aluminum isopropoxide in the powder form gradually added to it.

The molar ratio of alumina sol (ALP/ALN) was 3 so that the raw materials can be completely dissolved and provide 


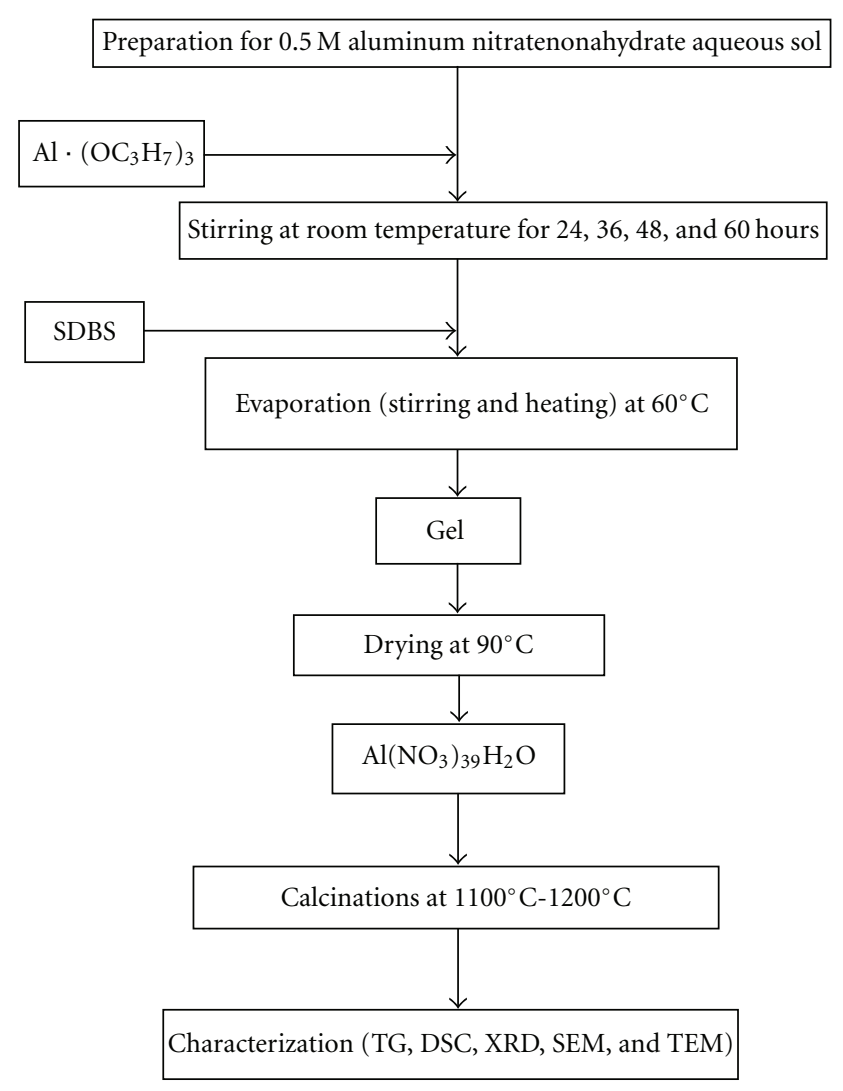

FIGURE 1: Nano- $\alpha$-alumina synthesis process.

clear solutions. The solutions were continuously stirred for 24, 36, 48, and 60 hours. Later, Sodium dodecylbenzen sulfonate (SDBS) was added by adjusting the molar ratio between alkoxide and surfactants to 0.1 and stirred for one hour. It is expected that the optimal time for the addition of surfactant is prior to the onset of the nucleation and growth step. The solutions were heated up to $60^{\circ} \mathrm{C}$ and stirred constantly for evaporation process. Viscosity and color changed as the sol turned into a transparent stick gel. The gels were, then, heat-treated at $90^{\circ} \mathrm{C}$ for 8 hours. Dried gels were calcined at temperature between 1000 and $1200^{\circ} \mathrm{C}$. Finally, the calcined powders crushed by using mortar and pestle.

Phase identifications were performed by X-ray Diffraction (XRD) using nickel-filtered $\mathrm{Cu} \mathrm{K} \alpha$ radiation in the range of $2 \theta=10^{\circ}-80^{\circ}$ with a scanning speed of $5^{\circ}$ per minute. The ultrasonic bath was applied to suspend calcined powder in ethanol, and subsequently, few droplets of it were used for microstructure evaluation by Phillips CM12 transmission electron microscopy (TEM) and Cambridge Stereoscan 200 and Leica Cambridge S-360 scanning electron microscopy (SEM). The process steps are illustrated in Figure 1.

\section{Results and Discussion}

The synthesis of nano- $\alpha-\mathrm{Al}_{2} \mathrm{O}_{3}$ was achieved through increasing the stirring time so that the excessive grain growth and aggregation of nanoparticles could be prevented. The

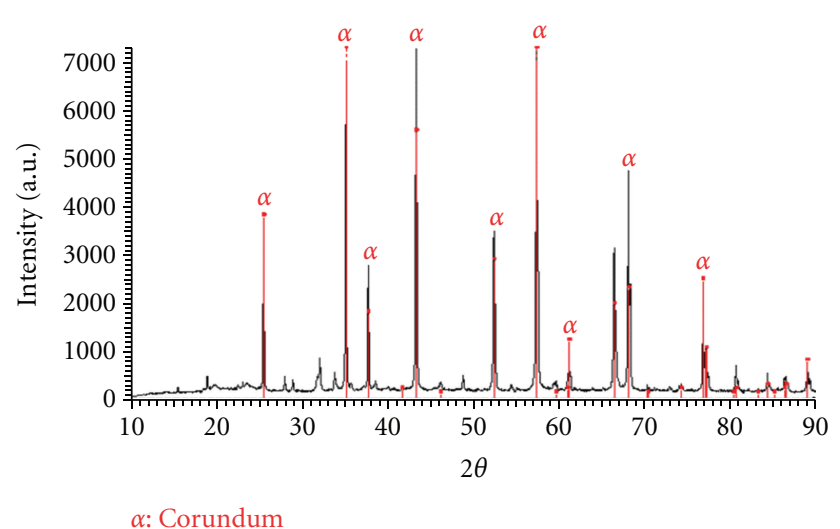

Figure 2: XRD spectra of $\mathrm{Al}_{2} \mathrm{O}_{3}$ at $1200^{\circ} \mathrm{C}$.

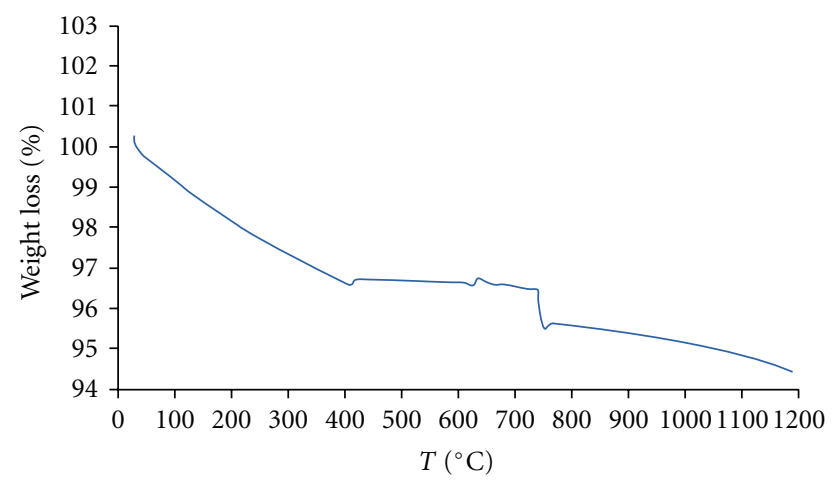

FIGURE 3: TGA curve of the as-synthesized precursor.

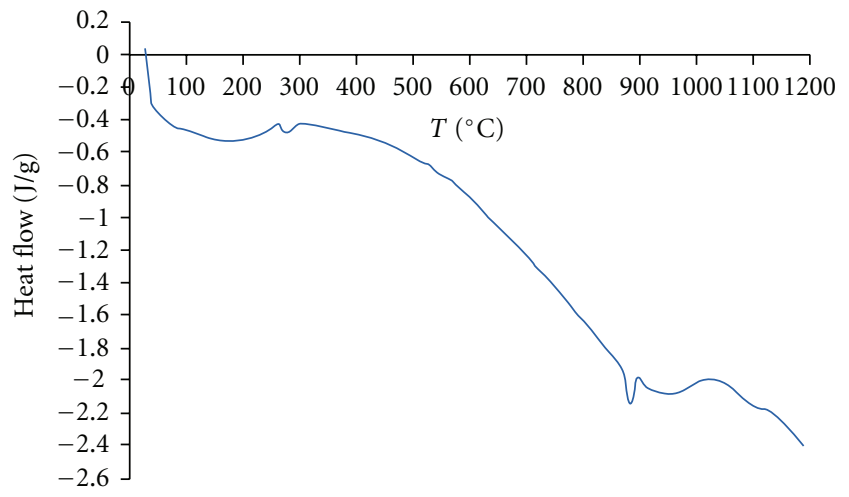

FIGURE 4: DSC curve of the as-synthesized precursor.

XRD analysis (Figure 2) showed the most stable phase, $\alpha$ $\mathrm{Al}_{2} \mathrm{O}_{3}$ occured dominantly at $1200^{\circ} \mathrm{C}$.

The observation reported by Hyuk-Joon et al. [9] indicated that completion of the most stable phase of $\alpha$-alumina occurs at this temperature. During thermal treatment, stable $\alpha-\mathrm{Al}_{2} \mathrm{O}_{3}$ phase can be obtained through the following series of phase transformation before conversion to $\alpha-\mathrm{Al}_{2} \mathrm{O}_{3}$ :

$$
\text { hydrous alumina } \longrightarrow \text { bohemite } \longrightarrow \gamma \longrightarrow \delta \longrightarrow \theta \longrightarrow \alpha
$$

(see [12]).

Figure 3 illustrates the TGA curve, at heating rate of $10^{\circ} \mathrm{C} / \mathrm{min}$ in air. There is a sharp decrease observed in 


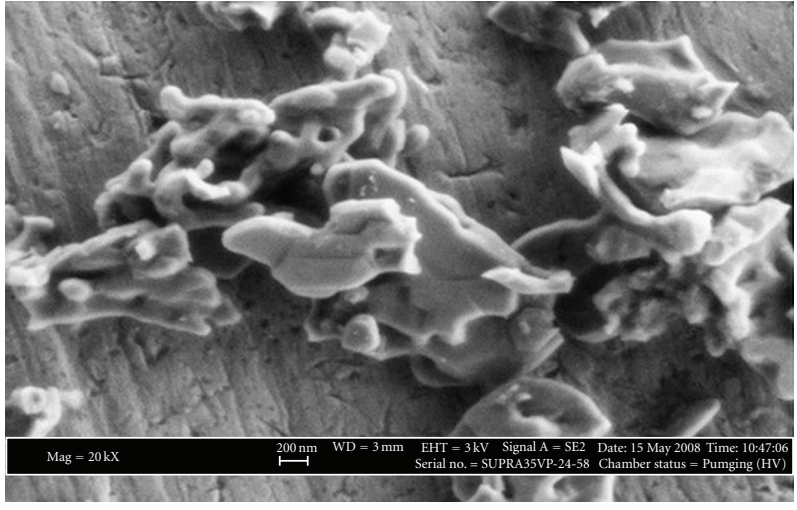

(a) $24 \mathrm{hr}$

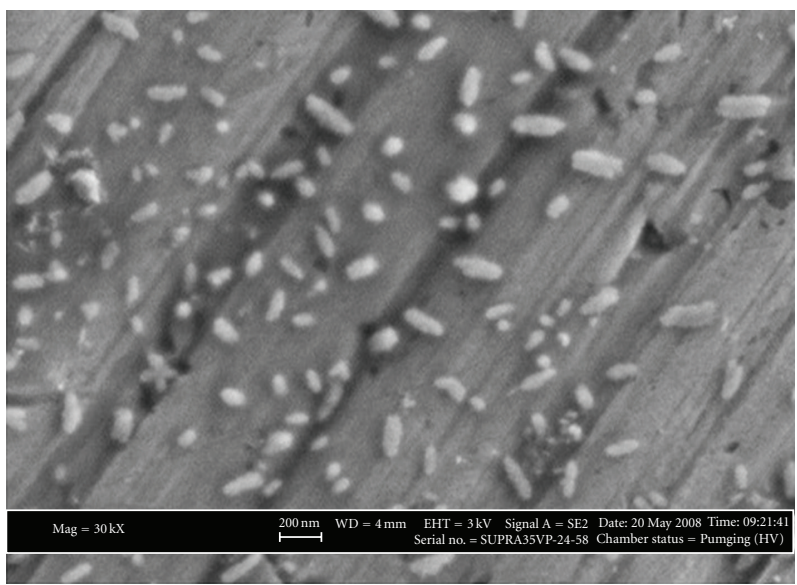

(c) $48 \mathrm{hr}$

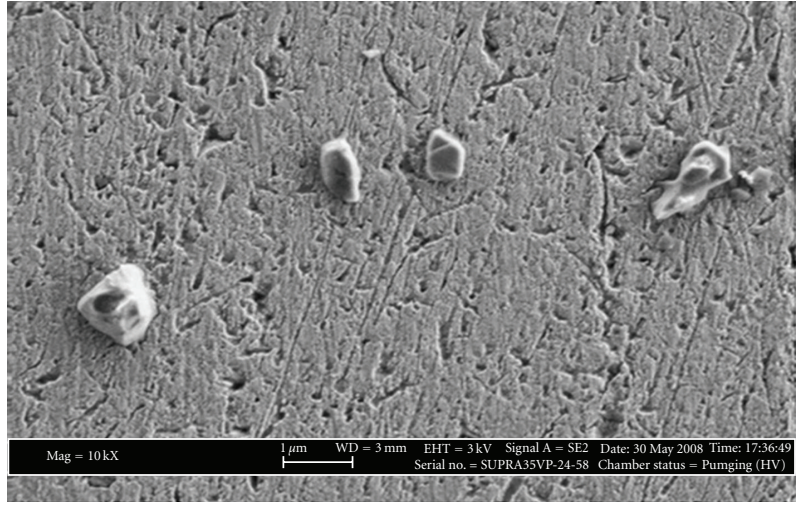

(b) $36 \mathrm{hr}$

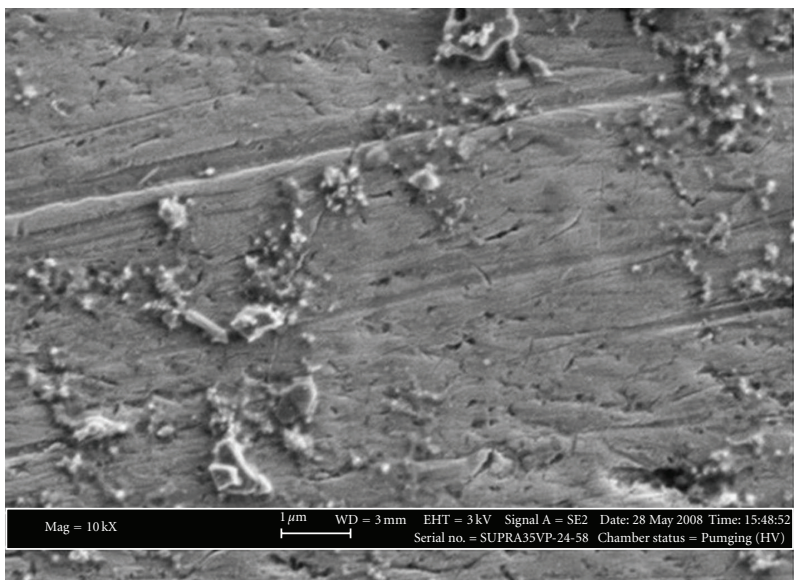

(d) $60 \mathrm{hr}$

FIGURE 5: SEM micrographs of $\alpha-\mathrm{Al}_{2} \mathrm{O}_{3}$ at different stirring time.

specimen weight $(\sim 6 \%)$ at temperature of $<400^{\circ} \mathrm{C}$; seemingly, this decrease is due to the elimination of the residual water content which is absorbed on the surface of nanocrystalline bohemite particles [10].

From $400-750^{\circ}$, weight loss of the mat is less than $1 \%$, and also there is less decrease in temperature. So, the volatilization does not happen obviously [11]. From 750 to $1200^{\circ} \mathrm{C}$, weight loss is observed again, and the temperature oscillates obviously, and it shows an exothermic reaction.

The DSC curve of the precursor is illustrated in Figure 4. In the temperature region of $25-270^{\circ} \mathrm{C}$, a broadened endothermic peak as well as a slight endothermic peak around $279.83^{\circ} \mathrm{C}$ emerges which is associated with the vaporization of physically bound absorbed water [2] and [12].

Three small exothermal peaks at 420,456 , and $479^{\circ} \mathrm{C}$ are attributed to the pseudomophic phase transformation of bohemite to $\gamma-\mathrm{Al}_{2} \mathrm{O}_{3}$. $[2,12,13]$. The endothermic peaks at 882 and $953^{\circ} \mathrm{C}$ are attributed to the phase transformation of $\gamma-\mathrm{Al}_{2} \mathrm{O}_{3}$ to $\delta-\mathrm{Al}_{2} \mathrm{O}_{3}$ and $\theta-\mathrm{Al}_{2} \mathrm{O}_{3}$. Also, $\alpha-\mathrm{Al}_{2} \mathrm{O}_{3}$ phase formation occurred at around 1035 and 1130 with two exothermic peaks [13]. This is in consistence with the XRD results which indicate that $\alpha-\mathrm{Al}_{2} \mathrm{O}_{3}$ phase occurred at 1100 $1200^{\circ} \mathrm{C}$.
Figure 5 shows SEM micrographs that by increasing the stirring time, the particle become finer and less agglomerated until 48 hour stirring. The particle started to agglomerate and to be more dense in structure at $60 \mathrm{~h}$.

Novakovic and Korthaus [7] and Hasmaliza et al. [5] had reported that drying of the sol invariably leads to agglomeration because the residual salts present in the sol as the water evaporates forms solid bridges between particles. Besides that, the particle size and shape of the $\alpha$-alumina is determined by the crystal structure of the original hydroxide and the series of phase transformations which occur during calcinations.

The TEM micrographs Figures (6(a), 6(b), 6(c), and $6(\mathrm{~d}))$ of the $\alpha-\mathrm{Al}_{2} \mathrm{O}_{3}$ particles show that the Particles, after 24,36 , and 60 hours of stirring, predominantly were in irregular angular shapes. As for the sample with stirring time of 48 hours, the particle shapes were mainly spherical Figure 6(c). The size of particles, after 24 hours of stirring, is in the range of $270-320 \mathrm{~nm}$ and had a lot of agglomeration, and the size of particles, after 36 hours of stirring, fell in the range of $250-300 \mathrm{~nm}$, and had a lot of agglomeration, but after 48 hours, the particle sizes were in the range of 20 $30 \mathrm{~nm}$ and had a good quality of dispersion. After 60 hours 


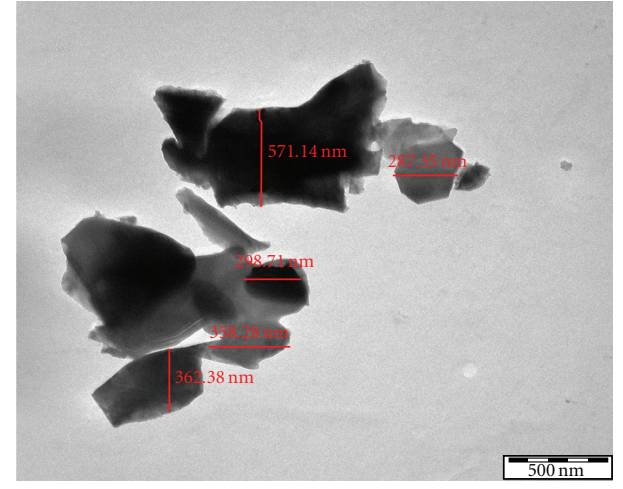

(a) $24 \mathrm{hr}$

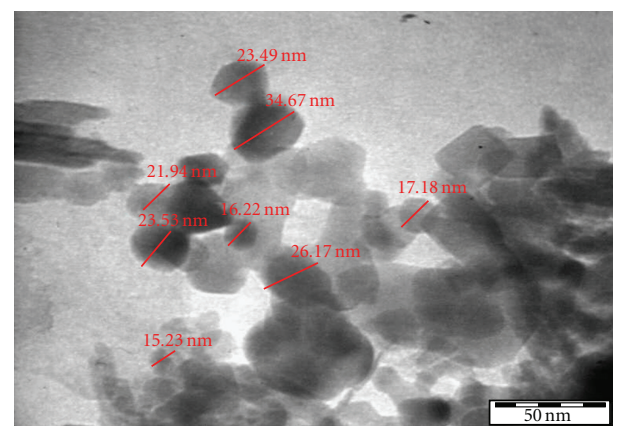

(c) $48 \mathrm{hr}$

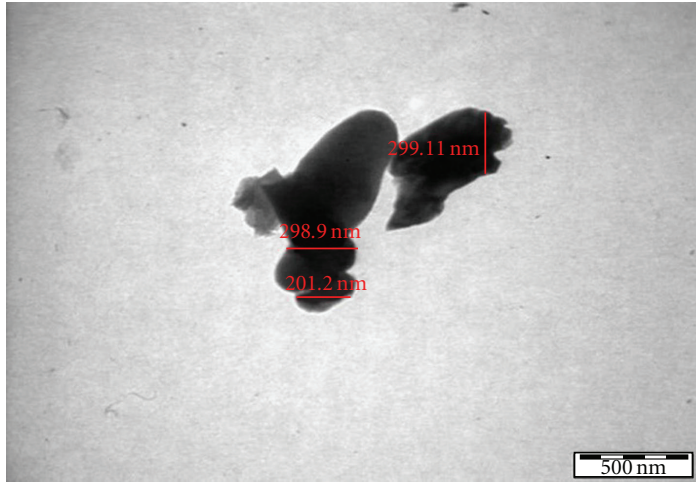

(b) $36 \mathrm{hr}$

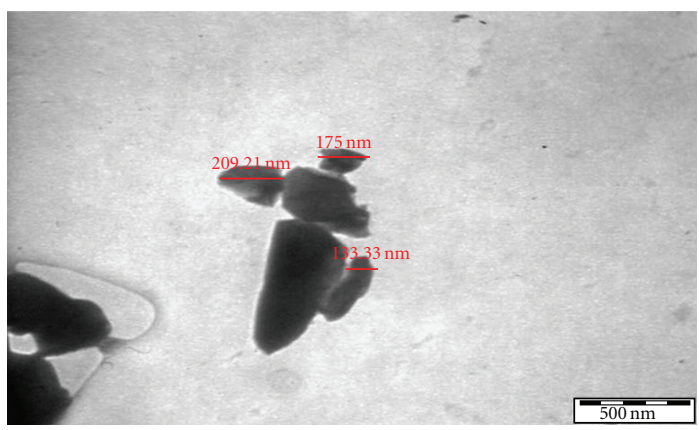

(d) $60 \mathrm{hr}$

Figure 6: TEM micrographs of $\alpha-\mathrm{Al}_{2} \mathrm{O}_{3}$ at different stirring time.

of stirring, the sizes of particles were in the range of 150 $200 \mathrm{~nm}$ and a lot of agglomeration and only little dispersion were observed.

Takhashi et al. [8] found that during stirring of the solution, the viscosity increased; therefore, the particle size improved but, due to the spinner revolution, the particle size decreased. As it proceeded, after 48 hours, more water evaporated from the sol, the supersaturated solution, thus, supplied the material necessary to bond colliding particles and form agglomerates. According to Lin et al. [14], agglomeration of solid products from two liquid ionic solutions A and $\mathrm{B}$ is as follows:

$$
\mathrm{An}^{+}+\mathrm{Bn}^{-} \longrightarrow \mathrm{C} \downarrow
$$

This reaction involves the instantaneous (mixing-controlled) chemical reaction, subsequent crystallization of the product (i.e., nucleation and growth of crystals), and its agglomeration.

At low supersaturation, there are usually negligible effects of agglomeration, and the crystals' size distribution is mainly affected by the competition between the nucleation and the growth of the crystal. However, at high supersaturation, the process is dominated by agglomeration.

As it proceeds, more water evaporates from sol, the supersaturated solution, thus, supplies the material necessary to bond colliding particles and form the agglomerates. Local concentrations, also, determine the electrical interaction between the small colloidal particles because most particles in aqueous media are charged and the resulting repulsion force depends on the solution composition.

Hence, due to these reasons, the agglomeration process enhances after 60 hours of stirring time, and there was strong agglomeration observed in the samples. This is in agreement with the observation of this study as shown in Figure 6(d).

Consequently, despite the high temperature $\left(1200^{\circ} \mathrm{C}\right)$, the obtained particle size ranged between 20 and $30 \mathrm{~nm}$ after 48 hours of stirring time. Furthermore, Wright and Sommerdijk [15] explained that the colloidal particles tend to obtain surface charge by ionization or adsorption of ions or polar molecules from the solution in stable sols. The charged surface layer, in turn, attracts a second more diffuse layer of ions of opposite charge in the neighboring solution. The van der waals attractive forces which potentially lead to aggregation fall as $r^{-6}$. On the other hand, the electrostatic repulsions vary as $r^{-1}$, between the link-charged ions of the diffuse layers around the nearest charged colloid particles.

Therefore, the repulsions dominate the vanderwaals attractions, and the particles are stable in opposition to the aggregation unless the thickness of the diffuse layer can be significantly decreased.

The main way in which the diffuse layer thickness can be decreased is raising the ionic strength of the solution, and in particular, increasing the charge on the counterion. Hence, the stirring time was effective in controlling the size of the particles and their degree of aggregation. 


\section{Conclusions}

In this research, the sol-gel method for the synthesis of aluminum oxide from aluminum alkoxide complexes was explained. However, selecting and controlling the exact stirring time for controlling the size of particles and the degree of aggregation are important. The evolution in the alumina precursor involved the decomposition which was followed by amorphous-to- $\gamma-\mathrm{Al}_{2} \mathrm{O}_{3}$ and $\gamma$-to- $\alpha-\mathrm{Al}_{2} \mathrm{O}_{3}$ phase transformation. Nano- $\alpha-\mathrm{Al}_{2} \mathrm{O}_{3}$ was observed at $1200^{\circ} \mathrm{C}$, when the transformation had just completed. The microstructural observation showed nanoscale $\alpha-\mathrm{Al}_{2} \mathrm{O}_{3}$ powder with 48 hours of stirring time were obtained in the range of 20-30 nm. Moreover, the particle size after 48 hours, in comparison with 24,36 , and 60 hours, generated a better dispersion as well as finer particles.

\section{Acknowledgment}

The authors would like to thank the Ministry of Science, Technology, and Innovation, Malaysia, University Putra Malaysia, and University Sains Malaysia in providing fund and support for this work.

\section{References}

[1] R. Aghababazadeh, A. R. Mirhabibi, J. Pourasad, A. Brown, A. Brydson, and N. Ameri Mahabad, "Economical synthesis of nanocrystalline alumina using an environmentally low-cost binder," Journal of Surface Science, vol. 601, no. 13, pp. 2864 2867, 2007.

[2] L. Jiang, P. Yubai, X. Changshu, G. Qiming, and J. Jingkun, "Low temperature synthesis of ultrafine $\alpha-\mathrm{Al}_{2} \mathrm{O}_{3}$ powder by a simple aqueous sol-gel process," Ceramics International, vol. 32, no. 5, pp. 587-591, 2005.

[3] G. M. Ming, J. Z. Ying, and L. X. Zi, "A new route to synthesis of $\gamma$-alumina nanorods," Materials Letters, vol. 61, no. 8-9, pp. 1812-1815, 2007.

[4] D. G. Wang, F. Guo, J. F. Chen, H. Liu, and Z. Zhang, "Preparation of nano aluminium trihydroxide by high gravity reactive precipitation," Chemical Engineering Journal, vol. 121, no. 2-3, pp. 109-114, 2006.

[5] M. Hasmaliza, S. S. How, and S. Rahayu, " $\alpha$-Alumina nanoparticle synthesize through sol-gel isopropoxide system," in Proceedings of the International Conference on Applied Production Technology (APT '07), Beijing, China, 2007.

[6] L. T. Geik, Y. L. Kong, and A. K. M. Wan, "Synthesis and characterization of sol-gel alumina nanofibers," Journal of SolGel Science and Technology, pp. 1-17, 2007.

[7] R. Novakovic and B. Korthaus, Advanced Ceramics for Use in Highly Oxidizing / Corrosive Environment, Trans Tech Publications, Switzerland.

[8] N. Takahashi, N. Kakuta, A. Ueno, K. Yamaguchi, and T. Fujil, "Characterization of iron oxide thin film prepared by the solgel method," Journal of Materials Science, vol. 26, no. 2, pp. 497-504, 1991.

[9] Y. Hyuk-Joon, W. J. Jin, T. K. Iu, and S. H. Kug, "Temperature formation of $\alpha$-alumina by doping of an alumina sol," Journal of Colloid and Interface Science, vol. 211, no. 1, pp. 110-113, 1999.
[10] C. C. Yong and J. Wang, "Mechanical—activation-triggered Gibbsite-to-Bohmite Transition and Activation-derived Alumina powders," Journal of the American Ceramic Society, vol. 84, no. 6, pp. 1225-1230, 2001.

[11] A. Sedaghat, E. Taheri-Nassaj, and R. Naghizadeh, "An alumina mat with a nano microstructure prepared by centrifugal spinning method," Journal of Non-Crystalline Solids, vol. 352, no. 26-27, pp. 2818-2828, 2006.

[12] H. Arami, M. Mazloumi, K. Khalifehzadeh, and S. K. Sadrnezhaad, "Bundles of self-assembled boehmite nanostrips from a surfactant free hydrothermal route," Journal of Alloys and Compounds, vol. 461, no. 1-2, pp. 551-554, 2008.

[13] Y. K. Park, E. H. Tadd, M. Zubris, and R. Tannenbaum, "Sizecontrolled synthesis of alumina nanoparticles from aluminum alkoxides," Materials Research Bulletin, vol. 40, no. 9, pp. 15061512, 2005.

[14] L. L. Sather, C. J. Lin, K. J. Lee, and N. J. Sather, "Slow motion of two spheres in a shear field," The Journal of Fluid Mechanics, vol. 43, pp. 45-47, 1970.

[15] J. D. Wright and N. A. J. M. Sommerdijk, Sol-gel Materials Chemistry and Applications, vol. 33431, Boca Raton, Fla, USA, 2001. 

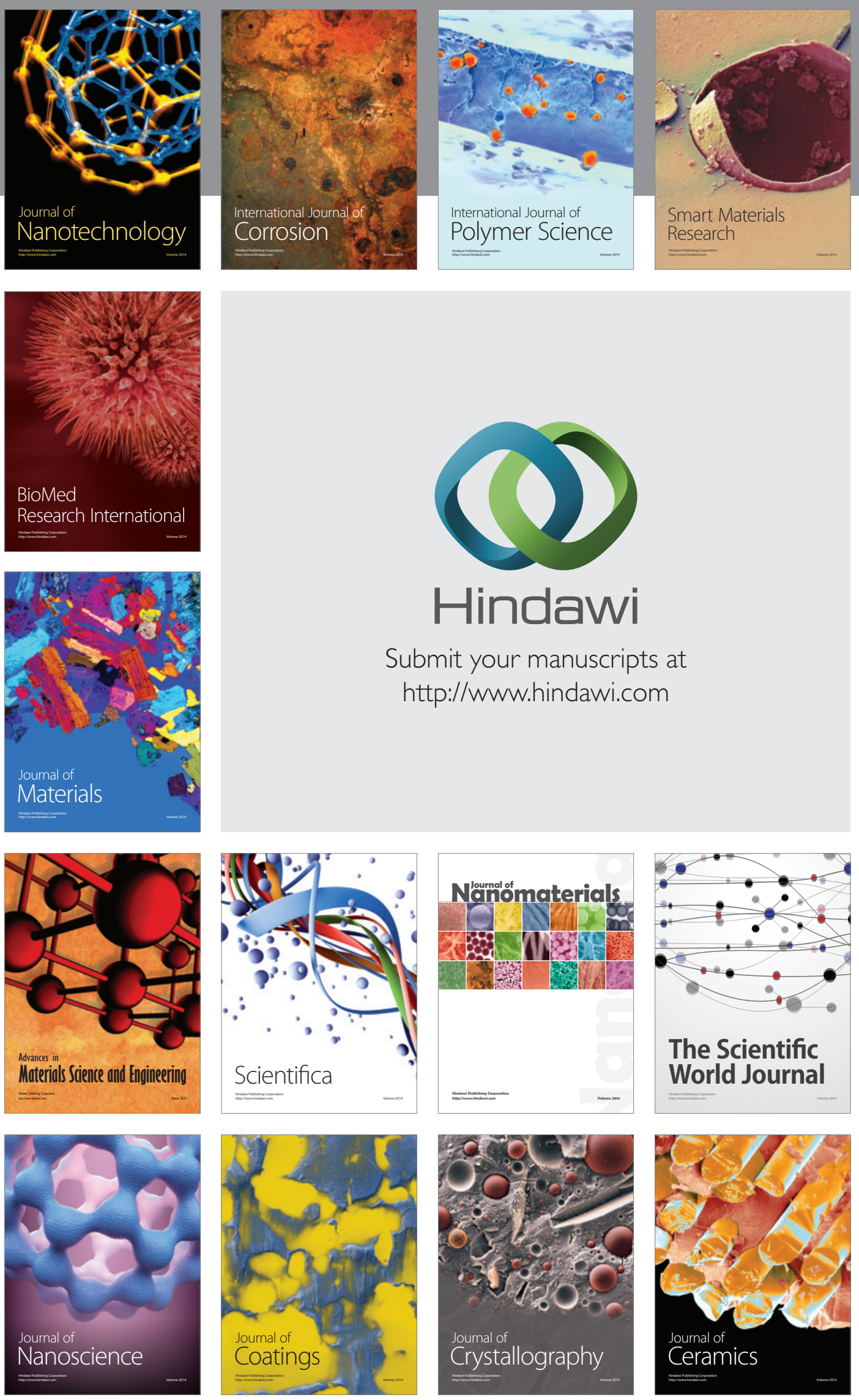

The Scientific World Journal

Submit your manuscripts at

http://www.hindawi.com

\section{World Journal}

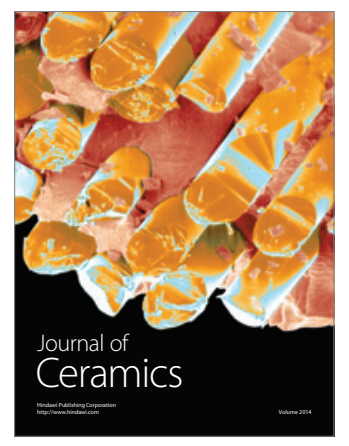

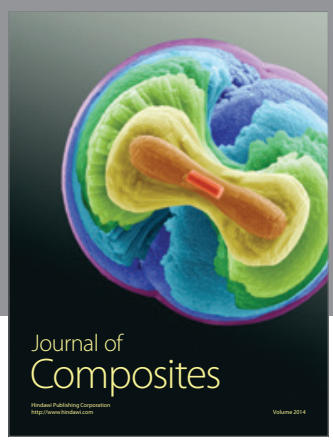
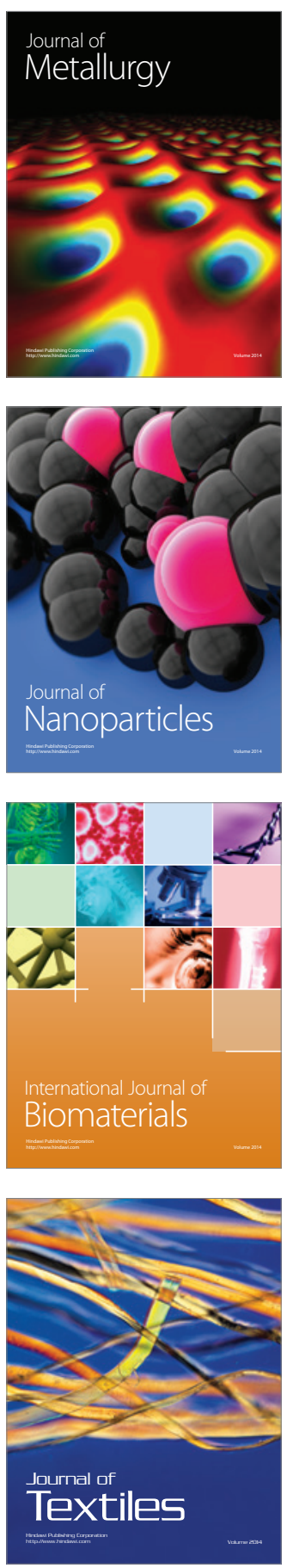